\title{
Black Smoke and Sulphur Dioxide in the Air as Risk Factors for Dry Eye Disease
}

\author{
Aleksandra Stankovic, Gordana Babic-Stankovic, Maja Nikolic, \\ Olivera Radulovic, Roberta Markovic, \\ Marija Andjelkovic Apostolovic*, Dejan Bonic
}

School of Medicine, University of Nis, Serbia

Received: 17 April 2018

Accepted: 28 May 2018

\begin{abstract}
The purpose was to study the effect of long-term exposure to ambient air pollution on the prevalence of dry eye disease (DED) among women. A total of 1356 women, who were recruited in two locations, with different levels of black smoke and sulphur dioxide from the city of Nis were examined to establish the prevalence of DED. A 13-point questionnaire, Tear film break-up time (TBUT), Schirmer's test and Rose Bengal test were used to diagnose dry eye. The univariate and multivariate regression analysis were used to investigate the relationship between long-tem exposure of air pollution and DED adjusted for potential confounding factors (age, passive smoking, keeping of pets, home dampness and use of biomass fuels). Multivariate logistic regression analysis demonstrated significant associations between the presence of DED and exposure to outdoor air pollution $(\mathrm{OR}=1.92,95 \% \mathrm{CI} 1.47-2.52, \mathrm{p}<0.001)$ and passive smoking $(\mathrm{OR}=1.13,95 \% \mathrm{CI} 1.04-1.64, \mathrm{p}<0.001)$. According to our study, exposure to outdoor air pollution of black smoke and sulphur dioxide appear to have a very significant effect on the occurrence of DED at women.
\end{abstract}

Keywords: ambient air pollution, dry eye disease, dry eye symptoms, women, passive smoking

\section{Introduction}

Dry eye is a significant and serious disease of the ocular surface that can greatly reduce quality of life [1]. According to Gayton [2], the prevalence of dry eye ranges from $7.4 \%$ to $33.7 \%$ and mainly depends on of the population that has been studied and how it is diagnosed. In Serbia, the morbidity rate from dry eye disease (DED) is still unknown. Diagnosing dry

*e-mail: drmari84@gmail.com eye is not always easy and simple due to the existence of various forms of dry eye and other disorders of the conjunctiva and cornea with very similar symptoms in its clinical manifestation.

In addition to the usual risk factors for DED such as age, gender, smoking, systemic diseases, and medications, some environmental factors may also play a role in its development following long-term exposure to them [3-5]. The effect of air pollutants on the eye may be different and depending on their composition and chemical properties, and mostly refers to discomfort and eye irritation. Experiments made on animals have shown that exposure of the eye to air pollution may affect the 
tear film stability [6, 7]. The disturbed homeostasis of a tear film maintained by delicate hormonal and neurological mechanisms leads to disorders of the lacrimal function and the scale of cellular reactions in which inflammation and cell apoptosis are closely related. Data from the literature confirm the influence of indoor air pollutants on eye irritation [8, 9]. Also, epidemiological studies have shown that exposure to ambient levels of air pollution is associated with clinical and histological changes of the eye [10, 11]. Previous studies on the impact of air pollution on the health of the Serbian population have mostly concerned respiratory, cardiovascular, and hematopoietic systems [12-14]. Ours is the first study in our country that deals with the impact of ambient air pollution on the eye.

In the present study we examined the effects of longterm exposure to black smoke and sulphur dioxide on the prevalence of DED among women.

\section{Material and Methods}

\section{Study Area and Population}

The study was conducted in the city of Niš in Serbia, which covers an area of $596.71 \mathrm{~km}^{2}$, and with a population of 392.340 . The two study areas (residential area - RA and suburban area - SA) of the city were carefully selected based on the significant difference in annual mean concentrations of sulphur dioxide $\left(\mathrm{SO}_{2}\right)$ and black smoke (BS) in the past 10 years.

A total of 1356 women (675 from RA and 681 from SA), aged between 20 and 45 years, were invited to participate. The following inclusion criteria were adopted: a) to have been living in the study area for at least 5 years, b) to have been living at a distance about of $5 \mathrm{~km}$ from an air monitoring station, b) to be nonsmokers, c) to have not been exposing to air pollutants in the workplace, d) to have an absence of some general diseases (cardiovascular disease, diabetes, thyroid disease, arthritis, and allergies) and lack of eye diseases (cataracts, glaucoma, uveitis, and Sjogren's syndrome), and e) no use of any medications and contact lenses.

The study protocol was approved by the ethics committee from the Institute of Public Health Niš. All volunteers were informed about the aim of the study and its performance and its expected results. Informed consent was obtained from each participant at each examination. The study was done from April to July 2016.

\section{Study Design}

Volunteers were invited to come to the Department of Ophthalmology to fill in a questionnaire and make a physical examination. After obtaining written informed consent, two questionnaires were used to collect baseline data and data of the symptoms of dry eye diseases by a trained ophthalmologist. Also, ocular examination was synchronously performed by an ophthalmologist.

\section{Environmental Exposure Assessment to Outdoor Air Pollution}

The concentrations of $\mathrm{SO}_{2}$ and $\mathrm{BS}$ from 2005 to 2015 were collected from the monitoring station in RA and SA. Air sampling and analyses were performed at the laboratory of the Public Health Institute in Nis. The laboratory is accredited to be compliant with ISO/IEC 17025 and ISO 9001 standards (SRPS ISO/ IEC 17025:2006; ISO 9001:2000). The pollutants are measured daily, during the whole year in and out of heating season. The sampling protocol was carried out by well-trained personnel. The air concentration of $\mathrm{SO}_{2}$ was determined by spectrophotometry. The ambient level of BS was measured by reflectance. Laboratory procedures for sample management, analytical methods, and quality control measures (accuracy, precision, and detection limits) are regulated by the relevant sections of Serbian law [15].

The exposure is assigned to each volunteer as the average value for each year in which the air pollution is measured.

\section{Questionnaires}

The general questionnaire included demographics, socioeconomics, and living conditions (e.g., exposure to biomass fuels, passive smoking (ETS) at home, home dampness, and the keeping of pets). For this analysis the following questions from the initial questionnaire were used:

- "Do you have a central heating system in the home?" - "If not, what type of heating material do you use?"

- "Does anyone smoke in the house?"

- "Have you ever had mould or mildew growing on any surface inside your present home?"

- "Have you got any pets in home?"

The symptoms of dry eye syndrome were validated using the questionaire suggested by Hikichi [16] and Toda [17]. The questionaire consisted of yes/no responses to 13 symptoms such as ocular fatigue, non-sticky eye discharge, foreign body sensation, heavy sensation, dry sensation, discomfort, ocular pain, watering, temporary blurred vision (improved on blinking), itching, photophobia, redness, and burning/stinging sensation. A response was defined as positive when the subject reported a symptom to occur sometimes, often, or all the time, and as negative when reported to occur rarely or never.

\section{Ocular Assessments}

The tests were carried out in sequence, tear break up time test (TBUT) followed by Schirmer test (ST) and 
Table 1. Characteristics of study participants.

\begin{tabular}{|c|c|c|c|}
\hline Variables & $\begin{array}{l}\text { Residential area } \\
\quad(\mathrm{n}=675)\end{array}$ & $\begin{array}{l}\text { Suburban area } \\
\quad(\mathrm{n}=681)\end{array}$ & p-value \\
\hline Age (Years), mean \pm SD & $38.43 \pm 7.2$ & $38.27 \pm 8.1$ & n.s. \\
\hline $\begin{array}{c}\text { Educational level, n (\%) } \\
\text { Elementary } \\
\text { Above elementary }\end{array}$ & $\begin{array}{l}176(26.1) \\
500(73.9)\end{array}$ & $\begin{array}{l}151(22.2) \\
530(77.1)\end{array}$ & n.s. \\
\hline ETS at home*,yes & $513(76)$ & $243(35.7)$ & $<0.001$ \\
\hline Use of biomass fuels*,yes & $130(19.2)$ & $263(38.6)$ & $<0.001$ \\
\hline Home dampness*,yes & $23(3.5)$ & $68(9.9)$ & $<0.001$ \\
\hline Keeping of pets*,yes & $112(16.6)$ & $225(33)$ & $<0.001$ \\
\hline
\end{tabular}

n.s. $=$ not statistically significant

*Significant difference exists between participants from RA and SA by $\chi^{2}$ test and Student's t-test.

Rose Bengal. This sequence was chosen to minimize any error caused due to reflex tearing.

\section{Schimer Test (ST)}

The test was performed using standardized strips of filter paper (Whatman's No. 41) and placed at the medial site of the lower lid margin in a temporal position [18]. No topical anesthesia was used and the examined area remained relaxed with open eyelids for $5 \mathrm{~min}$. The patient looked up and blinked normally for $5 \mathrm{~min}$ before the strip was removed and the length of wetted paper measured. A value of $<10 \mathrm{~mm}$ was taken as abnormal.

\section{Tear Break up Time Test (TBUT)}

The stability of the tear film over the conjunctiva and cornea was assessed using a slit lamp with a cobalt blue filter and sodium fluorescein. A drop of $2 \%$ sodium fluorescein was applied to the eye, and the examined was asked to blink five times so that a film is formed over the cornea and bulbar conjunctiva. The examined is then asked to refrain from blinking, during which time black spots or lines begin to appear indicating dry spots. The interval between the last blink and the first randomly distributed dry spot was taken as the tear break-up time. An average of three measurements was recorded. A value of $<10$ seconds is taken as abnormal [19].

\section{Rose Bengal Test}

After applying $10 \mathrm{ml}$ of $1 \%$ Rose Bengal solution, the Rose Bengal score was calculated [20]. No anesthetics or preservatives were used. The subjects were examined after a waiting period of $2 \mathrm{~min}$. The method described by Van Bijsterveld [21] was used to estimate the degree of staining.

\section{Statistical Analysis}

Statistical analysis is performed on a computer, according to the standard principles of descriptive and analytical statistical methodology, using standard programs for processing data such as Excel and software package SPSS in version 10.0. Comparison between the frequency of modality and occurrence of the tested characteristics is performed by nonparametric Pearson chi-squared test. A comparison of the average values is done by t-test. Air pollution data were analyzed using the Mann-Whitney $U$ test. Testing of correlation of individual characteristics is performed by regression analysis (SPSS), which establishes the type and strength of between the tested characteristics. Univariate and multivariate regression analyses were used to investigate the relationship between exposure of air pollution and DED, with adjustment for potential confounding factors (passive smoking, keeping of pets, home dampness, and the use of biomass fuels).

Table 2. Air pollution levels in residential and suburban areas of Nis from 2005 to $2015\left(\mu \mathrm{g} / \mathrm{m}^{3}\right)$.

\begin{tabular}{|c|c|c|c|c|}
\hline \multirow{2}{*}{ Air pollution levels } & \multicolumn{2}{|c|}{ Residential area } & \multicolumn{2}{c|}{ Suburban area } \\
\cline { 2 - 5 } & $\mathrm{BS}$ & $\mathrm{SO}_{2}$ & $\mathrm{BS}$ & $\mathrm{SO}_{2}$ \\
\hline Mean $( \pm \mathrm{SD})$ & $43.45( \pm 21.84)$ & $14.86( \pm 13.89)$ & $11.65( \pm 3.87)$ & $5.68( \pm 8.91)$ \\
\hline Median & 43 & 10 & 12 & 2 \\
\hline Minimum & 3 & 0.9 & 1 & 1.1 \\
\hline Maximum & 122 & 94 & 93 & 58.7 \\
\hline
\end{tabular}


Table 3. Prevalence of dry eye symptoms in subjects from residential and suburban areas.

\begin{tabular}{|c|c|c|c|c|}
\hline \multirow{2}{*}{ Dry eye symptoms } & \multicolumn{2}{|c|}{$\begin{array}{c}\text { Prevalence } \\
(\%)\end{array}$} & \multirow{2}{*}{$\mathrm{p}$-value } & \multirow{2}{*}{$95 \% \mathrm{CI}$} \\
\hline & $\begin{array}{l}\text { Residential area } \\
\quad(\mathrm{n}=675)\end{array}$ & $\begin{array}{l}\text { Suburban area } \\
\quad(\mathrm{n}=681)\end{array}$ & & \\
\hline Ocular fatigue* & 39.14 & 14.11 & $<0.001$ & $1.338-5.670$ \\
\hline Non-sticky eye discharge* & 29.34 & 10.19 & $<0.001$ & $1.071-2.664$ \\
\hline Foreign body sensation * & 20.11 & 9.08 & $<0.001$ & $1.233-3.454$ \\
\hline Heavy sensation & 4.12 & 3.98 & n.s. & $0.362-1.202$ \\
\hline Dry sensation* & 18.95 & 6.12 & $<0.001$ & $1.179-3.668$ \\
\hline Discomfort* & 67.90 & 21.34 & $<0.001$ & $1.432-5.112$ \\
\hline Ocular pain & 2.98 & 1.99 & n.s. & $0.655-1.979$ \\
\hline Watring* & 78.91 & 19.34 & $<0.001$ & $1.399-2.162$ \\
\hline Temporary blurred vision & 5.78 & 4.97 & n.s. & $0.463-1.468$ \\
\hline Itching* & 45.11 & 13.12 & $<0.001$ & $1.069-2.102$ \\
\hline Photophobia & 7.02 & 6.69 & n.s. & $0.547-2.110$ \\
\hline Redness & 6.98 & 6.01 & n.s. & $0.552-1.374$ \\
\hline Burning/stinging sensation & 4.39 & 3.05 & n.s. & $0.752-1.074$ \\
\hline
\end{tabular}

n.s. $=$ not statistically significant

* Significant difference exists between participants from residential and suburban areas by $\chi^{2}$ test.

\section{Results}

The baseline characteristics of all participants are shown in Table 1. Among the 1356 women participants analyzed, the average age was 38.54 years. Participants from RA and participants from SA were found to be statistically different across ETS at home, use of biomass fuels, home dampness, and keeping of pets.

Table 2 presents the arithmetic mean for $\mathrm{BS}$ and $\mathrm{SO}_{2}$ measured between 2005 and 2015 in the RA and the SA of Niš. The table shows only that the BS level in RA was above the guidelines set by the World Health Organization (WHO) guidelines $\left(20 \mu \mathrm{g} / \mathrm{m}^{3}\right.$ for BS and $20 \mu \mathrm{g} / \mathrm{m}^{3}$ for $\mathrm{SO}_{2}$ ) and Serbian National Ambient Air Quality Standards $\left(50 \mu \mathrm{g} / \mathrm{m}^{3}\right.$ for BS and $50 \mu \mathrm{g} / \mathrm{m}^{3}$ for $\mathrm{SO}_{2}$ ). All concentrations of the air pollutants measured at the air station in RA were higher when compared to the concentrations of the same pollutants measured at the SA. This difference is statistically significant (Mann-Whitney U test: $\mathrm{P}<0.05$ ).
Table 3 shows the prevalence of the dry eye symptoms among the examined. There was a higher prevalence of all symptoms among women from RA than in those from SA, which was statistically significant only for ocular fatigue, non-sticky eye discharge, foreign body sensation, dry sensation, discomfort, watering, and itching.

Table 4 shows the relationship among ocular tests and long-term exposure to air pollution. Subjects in the RA group had a higher frequency of abnormal Schirmer's test results, lower TBUT, and positive Rose Bengal tests relative to subjects in the SA. These differences were statistically significant.

Following are the results of univariate logistic regression analysis: keeping of pets, use of biomass fuels, and home dampness do not have a significant influence on the prevalence of DED. It is found that passive smoking $(\mathrm{p}<0.001)$ and exposure to outdoor air pollution $(\mathrm{p}<0.001)$ have a significant impact on the prevalence of DED (Table 5). Multivariate logistic

Table 4. Ocular tests affected in subjects from residential and suburban areas.

\begin{tabular}{|c|c|c|c|}
\hline Ocular test & $\begin{array}{c}\text { RA } \\
(\mathrm{n}=675)\end{array}$ & $\begin{array}{c}\text { SA } \\
(\mathrm{n}=681)\end{array}$ & p-value \\
\hline Schirmer's test (mm)* & $11.12 \pm 2.38$ & $21.98 \pm 5.34$ & $<0.001$ \\
\hline Tear film beak time (seconds)* $^{*}$ & $9.95 \pm 6.51$ & $18.39 \pm 4.31$ & $<0.001$ \\
\hline Rose Bengal & $8.79 \pm 4.322$ & $16.92 \pm 5.17$ & $<0.001$ \\
\hline
\end{tabular}

*Significant difference exists between participants from residential and suburban areas by Student's t- test. 
Table 5. Univariant logistic regression for dry eye disease.

\begin{tabular}{|c|c|c|c|c|}
\hline Characteristics & $\mathrm{B}$ & $\begin{array}{c}\text { Standard error } \\
(\mathrm{SE})\end{array}$ & $\mathrm{p}$ value & $\begin{array}{c}\text { Odds ratio (OR) }[95 \% \text { confidence interval } \\
(\mathrm{CI})]\end{array}$ \\
\hline Passive smoking & 0.521 & 0.222 & $<0.001$ & $1.68(1.09-2.60)$ \\
\hline Exposed/non-exposed to outdoor air pollution & 0.974 & 0.249 & $<0.001$ & $2.65(1.63-4.31)$ \\
\hline Keeping of pets & 0.242 & 0.184 & n.s. & $1.27(0.89-1.83)$ \\
\hline Home dampness & 0.366 & 0.220 & n.s. & $1.44(0.94-2.24)$ \\
\hline Use of biomass fuels & 0.034 & 0.221 & n.s. & $0.96(0.63-1.49)$ \\
\hline
\end{tabular}

n.s. $=$ not statistically significant

regression analysis demonstrated significant associations between the presence of dry eye syndrome and exposure to outdoor air pollution $(\mathrm{OR}=1.92,95 \% \mathrm{CI} 1.47-2.52$, $\mathrm{p}<0.001)$ and passive smoking $(\mathrm{OR}=1.13$, 95\%CI 1.04-1.64, $\mathrm{p}<0.001$ ) (Table 6).

\section{Discussion}

This investigation has shown that long-term air pollution exposure positively corresponds to the occurrence of DED among women in a reproductive period living in an urban area.

The major sources of air pollution are more present in the RA relative to the SA in the city of Nis. We have chosen to follow the impact of $\mathrm{SO}_{2}$ and $\mathrm{BS}$ because they are monitored constantly. Monitoring of other air pollutants is restricted by financial means and they are periodically monitored. Considering the results of the analyzed studies, it should be noticed that the average annual concentrations of $\mathrm{SO}_{2}$ and $\mathrm{BS}$ were below the current WHO guidelines and Serbian National Ambient Air Quality Standards. However, the values of concentrations of both measured pollutants in the SA were significantly lower in reference to the same measured values in the RA. Although concentrations of sulfur dioxide and black smoke have been significantly decreasing in the last 10 years, the present air concentrations in Niš are still an important threat to human health.

Air pollution is a mixture of a large number of pollutants and sometimes it is very difficult to determine the individual impact of each of them on eyes [22, 23]. There is substantial evidence that chronic exposure to ambient air pollution is associated with subclinical changes of the ocular surface and the tear film at people living in urban areas [24-26]. Different pollutants affect eyes differently. A study from South Korea [27] showed positive association between concentrations of $\mathrm{SO}_{2}$ and DED diagnosis (OR 1.092; 95\% CI 1.011-1.179) and DED symptoms (OR 1.092; 95\% CI 1.005-1.187) at people living in urban areas. Similar prevalence of DED symptoms was reported among the Thailand population by Wiwatanadate [28]. Another study performed in Korea [29] strongly confirmed the correlation between higher ozone and nitrogen dioxide levels and DED, while $\mathrm{PM}_{10}$ levels were not in correlation with DED. In contrast, Torricelli et al. [30] demonstrated an association between high levels of $\mathrm{PM}_{10}$ in large metropolitan areas with decreased tear breakup time and density of conjunctival goblet cells.

We found that the average results of Schirmer's test, TBUT and Rose Bengal were significantly lower at women from the RA compared to at women from the SA. Our results are consistent with the results of many other published studies in which the relationship between living area and DED was established. Study in New Delhi [31] reported that of 210 persons staying in the metropolis, $24 \%$ had an abnormal BUT, and 6.6\% had an abnormal Schirmer test. In contrast, of those 190 persons living outside the metropolis, only $5.2 \%$ had an abnormal BUT and 2\% had an abnormal Schirmer test. Another study in Delhi [32] analyzed the effect of environmental toxins on the ocular surface in persons travelling through highly polluted areas. The average Schirmer test result was $13.42+/-6.67 \mathrm{~mm}$ in the study group compared to $15.95+/-6.14 \mathrm{~mm}$ in the control group. This difference was statistically significant. The BUT was also significantly lower in the study group (12.97 \pm 6.12 seconds) compared to the control group $(19.23 \pm 5.70$ seconds $)(p<0.001)$. Since concentrations of air pollutants in urban areas are higher than in suburban ones because of the existence of various air pollution

Table 6. Multivariant logistic regression for dry eye disease.

\begin{tabular}{|c|c|c|c|c|}
\hline Characteristics & B & $\begin{array}{c}\text { Standard error } \\
(\mathrm{SE})\end{array}$ & p value & $\begin{array}{c}\text { Odds ratio (OR) [95\% confidence interval } \\
(\mathrm{CI})]\end{array}$ \\
\hline Passive smoking & 0.304 & 0.301 & $<0.001$ & $1.13(1.04-1.64)$ \\
\hline Exposed/non-exposed to outdoor air pollution & 0.654 & 0.138 & $<0.001$ & $1.92(1.47-2.52)$ \\
\hline
\end{tabular}


sources, it can be concluded that living in urban area is a risk factor for DED.

Many factors can affect dry eye prevalence. A study in China [33] confirmed that symptoms of dry eye were significantly associated with female gender (OR: 1.56; 95\% CI: 1.23-1.98) and age. Schaumberg et al. [34] reported that the prevalence of DES increased with age, from $5.7 \%$ among women $<50$ years old to $9.8 \%$ among women aged $>$ or $=75$ years old. Similar results were also shown by studies in Spain [35]. Nebbioso et al. [36] suggested that the reason for the increase of dry eye prevalence with age is a reduction in tear volume and flow and increases in evaporation. Women suffer more from eye symptoms than men and it is associated with hormonal changes [37]. Female hormones influence the function of the lacrimal gland in terms of the production of both the aqueous and lipid components of tears [38]. In our study, age was not a risk factor for DED. Our study has shown that not only women in menopause are at risk of developing DED, but they can also be women in the reproductive period. Outdoor and indoor low humidity may also be risk factors for DED. A low-humidity environment has a negative impact on some functions and characteristics of the eye, such as tear lipid layer thickness, tear stability, corneal epithelial integrity, evaporation rate, and visual quality [39, 40]. Several human studies have suggested that air pressure (altitude) can affect the occurrence of DED [41, 42].

Nevertheless, there are limitations to the present study. First, personal exposure to outdoor air pollutants were not measured, and we did not evaluate individual differences in exposure duration or intensity. Second, $\mathrm{PM}_{10}$ and $\mathrm{PM}_{2.5}$ were not investigated as air pollutants because these particles are measured at only one measuring site and data have no continuity. Third, seasonal and daily variations of air pollutants were not considered. Fourth, we do not examine the relationship between visual display terminal (VDT) use and the development of DED. Length of time of VDT use is a very important risk factor. Some authors [43-45] have suggested that more than 4 hours of VDT use among VDT users was associated with an increased risk of DED. Fifth, our study cannot control lipid levels of subjects. The lipid layer is an essential component of the tear film, providing a smooth optical surface for the cornea and retarding evaporation from the eye [46]. It is possible that levels of cholesterol in the lipid layer of tears depends on the level of serum cholesterol. Throughout the study we did not examine how weight effects the prevalence of DED. Different results concern the role of weight in the prevalence of dry eye syndrome. In a study by Koumi [47], a low body mass index (BMI) was a risk factor for DED in men, whereas high BMI was a preventive factor for DED in women. In contrast, a study by Moss et al. [48] included BMI as a not significant variable for DED.

Despite these limitations, this study has several strengths. We used objective testing for determining the existence of DED. We controlled several factors of indoor air pollution as potential confounding factors for DED in the statistical model. The results obtained are a baseline for further analytic epidemiological research. The strength of the present study was the exclusion selection of volunteers, leading to an underestimation of DED.

\section{Conclusions}

In conclusion, our study showed the association between long-term exposure to ambient air pollutant concentrations and DED in women of reproductive age. Following these observations, the present authors would strongly suggest including information about indoor air pollution and passive smoking exposure in a further study. The association between long-term exposure to ambient air pollutant concentrations and DED is appealing, but further confirmation studies are still necessary.

\section{Acknowledgements}

This study was published thanks to the Ministry of Science and Technological Development of the Republic of Serbia (project Nos. 42008 and 43014).

\section{Conflict of Interest}

The authors declare no conflict of interest.

\section{References}

1. NA K.S., HAN K., PARK Y.G., NA C., JOO C.K. Depression, Stress, Quality of Life, and Dry Eye Disease in Korean Women: A Population-Based Study. Cornea. 34 (7), 733, 2015.

2. GAYTON J.L. Etiology, prevalence, and treatment of dry eye disease. Clin Ophthalmol. 3, 405, 2009.

3. AHN J.M., LEE S.H., RIM T.H., et al. Prevalence and risk factors associated with dry eye: the Korea National Health and Nutrition Examination Survey 2010-2011. Am J Ophthalmol. 158, 1205, 2014.

4. FARRAND K.F., FRIDMAN M., STILLMAN I. Ö., SCHAUMBERG D.A. Prevalence of Diagnosed Dry Eye Disease in the United States Among Adults Aged 18 Years and Older. Am J Ophthalmol. 182, 90, 2017.

5. GALOR A., KUMAR N., FEUER W., LEE D.J. Environmental factors affect the risk of dry eye syndrome in a United States veteran population. Ophthalmology. 121, 972, 2014.

6. BARABINO S., DANA M.R. Animal models of dry eye: a critical assessment of opportunities and limitations. Invest Ophthalmol Vis Sci. 45, 1641, 2004.

7. EOM Y., SONG J.S., LEE D.Y., et al. Effect of titanium dioxide nanoparticle exposure on the ocular surface: an animal study. Ocul Surf. 14, 224, 2016.

8. LU C.Y., LIN J.M., CHEN Y.Y., CHEN Y.C. Buildingrelated symptoms among office employees associated 
with indoor carbon dioxide and total volatile organic compounds. Int J Environ Res Public Health. 12 (6), 5833, 2015.

9. WOLKOFF P. External eye symptoms in indoor environments. Indoor Air. 27, 246, 2017.

10. CHANG C.J., YANG H.H., CHANG C.A., TSAI H.Y. Relationship between air pollution and outpatient visits for nonspecific conjunctivitis. Invest Ophthalmol Vis Sci. 53, 429, 2012.

11. HAN J.Y., KANG B., EOM Y., KIM H.M., SONG J.S. Comparing the effects of particulate matter on the ocular surfaces of normal eyes and a dry eye rat model. 36, 605, 2017.

12. MILUTINOVIĆ S., NIKIĆ D., STOSIĆ L., STANKOVIĆ A., BOGDANOVIĆ D. Short-term association between air pollution and emergency room admissions for chronic obstructive pulmonary disease in Nis, Serbia. Cent Eur J Public Health. 17 (1), 8, 2009.

13. STANKOVIĆ A., NIKOLIĆ M., ARANDJELOVIĆ M. Effects of Air Pollution on Blood Pressure of Pregnant Women. Pol.J. Environ. Stud. 21 (2), 465, 2012.

14. NIKOLIĆ. M., NIKIĆ. D., STANKOVIĆ A. Effects of air pollution on red blood cells in children.Pol. J. Environ. Stud. 17 (2), 267, 2008.

15. Ministry for Protection of Natural Resources and Environment of Serbia. The Regulation on conditions for monitoring and air quality requirements, Official Journal of the Republic of Serbia, 2013, no. 11/10, 75/10 and 63/13. [In Serbian].

16. HIKICHI T., YOSHIDA A., FUKUI Y. et al. Prevalence of dry eye in Japanese eye centers. Graefes Arch Clin Exp Ophthalmol. 233, 555, 1995.

17. TODA I., FUJISHIMA H., TSUBOTA K. Ocular fatigue is the major symptom of dry eye. Acta Ophthalmol. 71, 347, 1993.

18. SCHIRMER O. Studien zur physiologie und pathologie der tranen-absonderung und tranenabfuhr. Graefes Arch Clin Exp Ophthalmol. 56, 197, 1903.

19. NORN M.S. Desiccation of the precorneal film and corneal wetting-time. Acta Ophthalmol. 47, 865, 1969.

20. NORN M.S. Rose Bengal. In: Norn MS, ed. External Eye. Methods of Examina-tion. Copenhagen, 60, 1983.

21. VAN BIJSTERVELD O.P. Diagnostic tests in the sicca syndrome. Arch Ophthalmol. 82, 10, 1969.

22. JUNG S.J., MEHTA J.S., TONG L. Effects of environment pollution on the ocular surface. Ocul Surf. 16 (2), 198, 2018.

23. SZYSZKOWICZ M., KOUSHA T., CASTNER J. Air pollution and emergency department visits for conjunctivitis: a case-crossover study. Int J Occup Med Environ Health. 29, 1, 2016.

24. TORRICELLI A.A., MATSUDA M., NOVAES P., et al. Effects of ambient levels of traffic-derived air pollution on the ocular surface: analysis of symptoms, conjunctival goblet cell count and mucin 5AC gene expression. Environ Res. 131, 59, 2014.

25. TORRICELLI A.A., NOVAES P., MATSUDA M., ALVES M.R., MONTEIRO M.L. Ocular surface adverse effects of ambient levels of air pollution. Arq Bras Oftalmol. 74, 377, 2011.

26. HAN S.B., HYON J.Y., WOO S.J., LEE J.J., KIM T.H., KIM K.W. Prevalence of dry eye disease in an elderly Korean population. Arch Ophthalmol. 129 (5), 633, 2011.

27. UM S.B., KIM N.H., LEE H.K., SONG J.S., KIM H.C. Spatial epidemiology of dry eye disease: findings from South Korea. Int J Health Geogr. 13, 31, 2014.
28. WIWATANADATE P. Acute air pollution-related symptoms among residents in Chiang Mai, Thailand. J Environ Health. 76 (6), 76, 2014.

29. HWANG S.H., CHOI Y.H., PAIK H.J., WEE W.R., KIM M.K., KIM D.H. Potential Importance of Ozone in the Association Between Outdoor Air Pollution and Dry Eye Disease in South Korea. JAMA Ophthalmol. 134 (5), 503, 2016.

30. TORRICELLI A.A., NOVAES P., MATSUDA M., et al. Correlation between signs and symptoms of ocular surface dysfunction and tear osmolarity with ambient levels of air pollution in a large metropolitan area. Cornea. 32 (4), e11, 2013.

31. GUPTA S.K., GUPTA V., JOSHI S., TANDON R. Subclinically dry eyes in urban Delhi: an impact of air pollution? Ophthalmologica. 216, 368, 2002.

32. SAXENA R., SRIVASTAVA S., TRIVEDI D., ANAND E., JOSHI S., GUPTA S.K. Impact of environmental pollution on the eye. Acta Ophthalmol Scand. 81, 491, 2003.

33. JIE Y., XU L., WU Y.Y., JONAS J.B. Prevalence of dry eye among adult Chinese in the Beijing eye study. Eye. $\mathbf{2 3}$ (3), 688, 2009.

34. SCHAUMBERG D.A., SULLIVAN D.A., BURING J.E., DANA M.R. Prevalence of dry eye syndrome among US women. Am J Ophthalmol. 136 (2), 318, 2003.

35. VISO E., RODRIGUEZ-ARES M.T., GUDE F. Prevalence of and associated factors for dry eye in a Spanish adult population (the Salnes Eye Study). Ophthalmic Epidemiol. 16 (1), 15, 2009.

36. NEBBIOSO M., DEL REGNO P., GHARBIYA M., SACCHETTI M., PLATEROTI R., LAMBIASE A. Analysis of the Pathogenic Factors and Management of Dry Eye in Ocular Surface Disorders. Int J Mol Sci. 18, E1764, 2017.

37. SCHAUMBERG D.A., UCHINO M., CHRISTEN W.G., SEMBA R.D., BURING J.E., LI J.Z. Patient reported differences in dry eye disease between men and women: impact, management, and patient satisfaction. PLoS One. 8, e76121, 2013.

38. SRIPRASERT I., WARREN D.W., MIRCHEFF A.K., STANCZYK F.Z. Dry eye in postmenopausal women: A hormonal disorder. Menopause. 23, 343, 2016.

39. ABUSHARHA A.A., PEARCE E.I. The effect of low humidity on the human tear film. Cornea. 32 (4), 429, 2013.

40. LÓPEZ-MIGUEL A., TESÓN M., MARTÍNMONTAÑEZ V., et al Dry eye exacerbation in patients exposed to desiccating stress under controlled environmental conditions. Am J Ophthalmol. 157 (4), 788e2, 2014.

41. WILLMANN G., SCHATZ A., FISCHER M.D., et al. Exposure to high altitude alters tear film osmolarity and breakup time. High Alt Med Biol. 9, 327, 2014.

42. GALOR A., KUMAR N., FEUER W., LEE D.J. Environmental factors affect the risk of dry eye syndrome in a United States veteran population. Ophthalmology. 121, 972, 2014.

43. UCHINO M., SCHAUMBERG D.A., DOGRU M. Prevalence of dry eye disease among Japanese visual display terminal users. Ophthalmology. 115, 1982, 2008.

44. YOKOI N., UCHINO M., UCHINO Y., et al. Importance of tear film instability in dry eye disease in office workers using visual display terminals: the Osaka study. Am J Ophthalmol. 159, 748, 2015. 
45. YAZICI A., SARI E.S., SAHIN G., et al. Change in tear film characteristics in visual display terminal users. Eur J Ophthalmol. 25 (2), 85, 2015.

46. BRON A.J., TIFFANY J.M., GOUVEIA S.M., YOKOI N., VOON L.W. Functional aspects of the tear film lipid layer. Exp Eye Res, 78, 347, 2004.
47. UCHINO M., NISHIWAKI Y., MICHIKAWA T. Prevalence and risk factors of dry eye disease in Japan: Koumi study. Ophthalmology. 118, 2361, 2011.

48. MOSS S.E., KLEIN R., KLEIN B.E. Prevalence of and risk factors for dry eye syndrome. Arch Ophthalmol. 118, 1264,2000 